\title{
PSICOLOGIA E TRABALHO INFORMAL: A PERSPECTIVA DOS PROCESSOS DE SIGNIFICAÇÃO
}

PSICOLOGÍA Y TRABAJO INFORMAL: LA PERSPECTIVA DE LOS PROCESOS DE SIGNIFICACIÓN

PSYCHOLOGY AND INFORMAL WORK: THE MEANING-MAKING PERSPECTIVE

http://dx.doi.org/10.1590/1807-03102015v27n2p383

Pedro F. Bendassolli e Fellipe Coelho-Lima

Universidade Federal do Rio Grande do Norte, Natal/RN, Brasil

\begin{abstract}
RESUMO
O presente artigo tem como objetivo apresentar e discutir um modelo teórico acerca da significação no trabalho, explorando suas consequências, na forma de desafios e possibilidades, para a pesquisa em psicologia sobre o trabalho informal. O processo de significação é constituído por três componentes: os significados produzidos e disseminados coletivamente sobre o trabalho; os sentidos, apreensões singulares daqueles significados; e a atividade, que serve de mediação entre o sujeito e a realidade, colocando em ação os sentidos e significados. $\mathrm{O}$ artigo também discute algumas características que definem o trabalho informal. Por fim, desenvolve três hipóteses de pesquisa: que o recorte do processo de significação permite ao pesquisador apreender as tensões entre formal/informal; que ele contribui para a consideração e diferenciação de distintos níveis na análise do fenômeno da informalidade; e que tal recorte contribui para uma compreensão não exclusivamente cognitivista e individualista sobre sentidos e significados do trabalho.
\end{abstract}

Palavras-chave: sentidos do trabalho; significação no trabalho; trabalho informal.

\section{RESUMEN}

El presente artículo tiene como objetivo presentar y discutir un modelo teórico acerca de la significación en el trabajo, explorando sus consecuencias, en forma de retos y posibilidades para la investigación en psicología sobre el trabajo informal. El proceso de significación se constituye por tres componentes: los significados producidos y diseminados colectivamente sobre el trabajo; los sentidos, comprensiones singulares de aquellos significados; y la actividad, que se sirve de una mediación entre el sujeto y la realidad, colocando en acción los sentidos y la significación. El artículo también discute algunas características que definen el trabajo informal. Por fin, se desarrollan tres hipótesis de investigación: que el recorte del proceso de investigación permite al investigador comprender las tensiones entre lo formal y lo informal; que él contribuye para la consideración y la diferenciación de distintos niveles en el análisis del fenómeno de la informalidad; y que tal recorte contribuye para una compresión que no exclusivamente cognitivista o individualista sobre los sentidos u el significado del trabajo.

Palabras-clave: sentidos del trabajo; significación en el trabajo, trabajo informal.

\begin{abstract}
This paper aims to present and discuss a theoretical meaning-making model in work, exploring the challenges and possibilities it brings to the psychological research about informal work. The meaning-making process comprises three components: the social and collective meanings about work; the sense of work defined as a singular apprehension of those meanings; and the activity - which mediates the relation between subject and social reality, putting into action both meaning and sense. The paper develops three hypotheses: firstly, that the meaning-making approach allows the researcher grasp the tension between formal/informal labor; secondly, it helps him tell apart different levels of analysis on the informality phenomenon; and thirdly, this approach also contributes to a broader comprehension of meanings and sense in the work place, not only in cognitive and individualist terms.
\end{abstract}

Keywords: sense of work; meaning-making in work; informal work. 


\section{Introdução}

Estima-se que, no Brasil, $27 \%$ da população economicamente ativa (PEA) trabalhem na informalidade (IGBE, 2014). O fenômeno da informalidade caracteriza-se, do ponto de vista do trabalho, por uma diversidade de arranjos laborais, contextos produtivos, bens e serviços produzidos, condições de trabalho e relacionamento com as instituições do Estado (Cardoso, 2013). Em larga medida, é reflexo de uma heterogeneização do trabalho na atual etapa do capitalismo (Alves \& Tavares, 2006; Antunes, 2011; Tavares, 2010).

Do ponto de vista psicossocial, a informalidade compreende igualmente uma diversidade de modalidades de interação, sociabilidades, trajetórias laborais, competências, motivações, sentidos e significados (Gómez, 2011; Sato, 2013; Spink, 2009). Como consequência, traz desafios ao subdomínio da psicologia dedicado ao estudo da relação sujeito-trabalho, notadamente à Psicologia Social do Trabalho, cujo leque de preocupações tem se ampliado para além das temáticas associadas às organizações capitalistas tradicionais.

É nesse contexto que o estudo da informalidade ganha espaço, como se pode apreender de algumas pesquisas recentes (e.g., Cunha \& Vieira, 2009; Fernandes \& Araújo, 2012; Sato, 2009, 2013; Spink, 2009). Tais estudos privilegiam distintos ângulos de análise sobre o fenômeno, tais como relações sociais (sociabilidades), condições de trabalho, bem-estar subjetivo, saúde, qualidade de vida, processos organizativos. Menos comuns, porém, são estudos explicitamente voltados à análise de processos de produção de sentidos e significados na informalidade, e de suas potenciais consequências. O presente artigo se propõe a contribuir nessa direção, apresentando argumentos em favor de estudos que privilegiem a dimensão subjetiva do trabalho informal - mais especificamente, o processo de significação no trabalho, entendido como a combinação dinâmica entre sentidos, significados e atividade.

A escolha por esse recorte baseia-se em alguns pressupostos e hipóteses. Primeiro, no pressuposto de que o trabalho é uma forma de mediação do homem com a natureza, social e não social. E que, no transcurso de tal processo, ele produz sentidos e significados, os quais, conjuntamente com os objetos gerados, compõem o universo simbólico e material em que habita (cultura). Segundo, que a existência desses sentidos e significados é dependente do fato de o trabalho ser uma atividade intencional, cuja reflexão acontece pela linguagem, pelo "falar sobre".
Esse falar sobre, de cunho reflexivo, permite a contínua (re)elaboração do agir no trabalho. Terceiro, a introdução da atividade contribui para que a análise dos sentidos e significados se enraíze no contexto do trabalho real, e não no trabalho abstrato.

Desses pressupostos, emergem algumas hipóteses, as quais norteiam a argumentação proposta neste artigo. A primeira consiste na possibilidade de que a análise dos sentidos e significados - ou seja, do processo de significação - nos permita refletir sobre as tensões entre formal/informal. Segunda, de que tal ângulo nos permite explorar a relação entre níveis de análise - o indivíduo (nível do singular, do particular, do sentido), e o nível coletivo-social - no qual estão presentes os significados compartilhados e relativamente estabilizados. Terceira hipótese, a análise do processo de significação permite sua fundação na atividade, isto é, no fazer concreto do sujeito. Esta última hipótese questiona as tentativas de investigar sentidos e significados a partir de dimensões exclusivamente cognitivistas, com pouca referência à atividade, ao fazer situado do trabalhador.

Para discutir tais pressupostos e hipóteses, o artigo propõe um modelo teórico em que as diversas dimensões de interesse são articuladas entre si (Figura 1). Metodologicamente, a lógica do artigo consiste em descrever e problematizar esse modelo. Assim, num primeiro momento serão discutidas as bases teórico-conceituais do que se chama aqui de processo de significação. Em seguida, discutimos a própria informalidade, no sentido de compreender algumas de suas características, as quais formam o contexto em que os referidos processos de significação ocorrem. E, por fim, integramos as discussões anteriores, propondo alguns encaminhamentos para a investigação dos processos de significação na informalidade, com especial preocupação em contribuir para a diversificação temática da psicologia em seu encontro com o trabalho, tornando-se ainda mais sensível e crítica com respeito à heterogeneidade do trabalho na contemporaneidade.

\section{Processo de significação e trabalho}

Antes da apresentação do núcleo da Figura 1 (processo de significação), é importante contextualizar a literatura sobre sentidos e significados do trabalho, cujas primeiras investigações remontam aos anos de 1950 (e.g., Morse \& Weiss, 1955). Ao longo dessas décadas, várias terminologias foram sendo empregadas para se referir à significação do trabalho. Considerando particularmente o contexto brasileiro, 
Figura 1. Modelo de investigação sobre processos de significação no trabalho

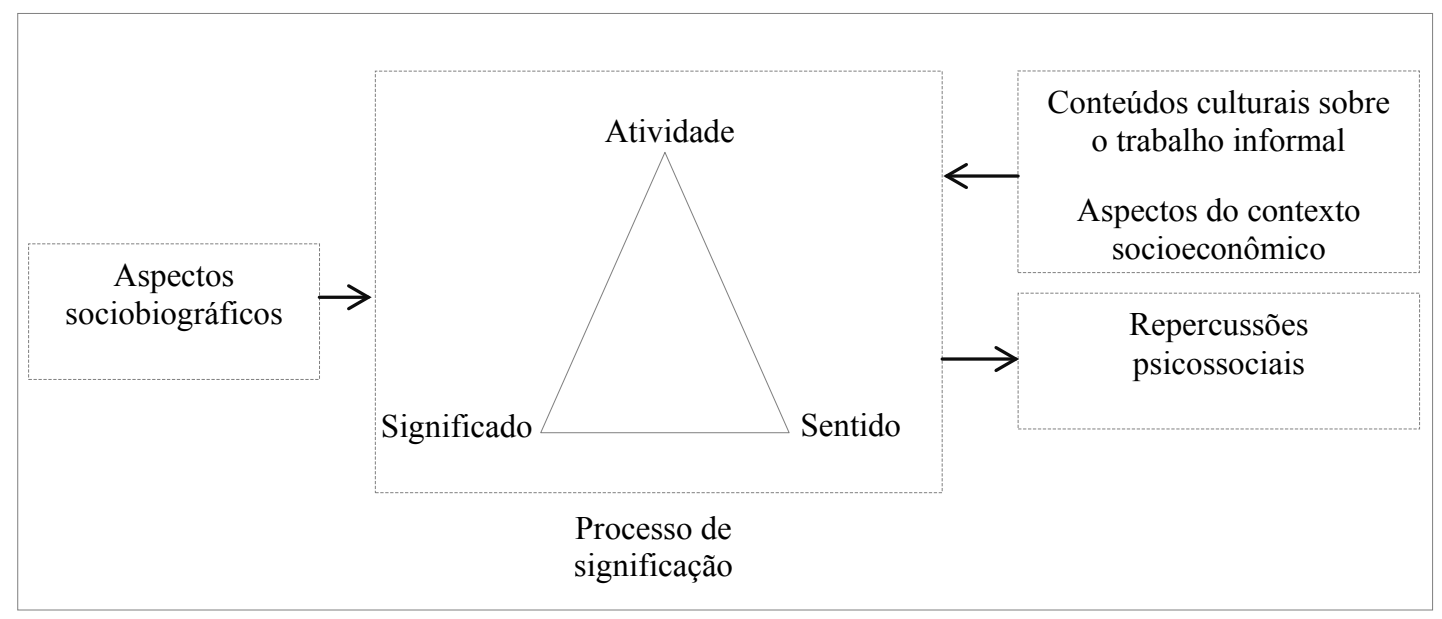

há autores que utilizam o termo, mais tradicional, significado(s) do trabalho (e.g., Borges, 1997; Fernandes, Gonçalves, \& Oliveira, 2012; Goulart, 2009), e há também, sobretudo na última década, os que optam pelo uso de sentido(s), explicando sua suposta diferença relativamente à perspectiva anterior (e.g., Bendassolli \& Borges-Andrade, 2011; Tolfo \& Piccinini, 2007; Tolfo, Coutinho, Baasch, \& Gugnier, 2011). Outros autores simplesmente utilizam sentidos e significados indistintamente (e.g., Lourenço, Ferreira, \& Brito, 2013; Oliveira \& Silveira, 2012).

A perspectiva dos significados do trabalho é representada pelos estudos do Meaning of Work Team (MOW, 1987), nos quais os significados são considerados um fenômeno multifacetado, influenciado por aspectos sociais, econômicos e culturais, sendo composto por três dimensões: centralidade, dimensões socionormativas e resultados, e objetivos valorizados. Já os estudos sobre sentido são, no contexto brasileiro, influenciados pelas pesquisas de Morin (2001, 2007), para quem esse constructo possui três dimensões: significação (definição de trabalho), orientação (por que se trabalha) e coerência (equilíbrio entre o self e o trabalho).

Neste artigo, assumimos a diferença entre sentidos e significados do trabalho, no que nos alinhamos, em termos mais amplos, à perspectiva sócio-histórica (Vygotski, 1993a, 1993b) e, mais especificamente, às teorias da atividade (e.g.: Bedny \& Karwowski, 2007; Bendassolli, 2012; Clot, 1999, 2008; Wertsch, 1981). Desse modo, no modelo proposto na Figura 1, sentidos e significados, embora distintos entre si individualmente, compõem uma unidade indivisível, mediada pela atividade. Portanto, ambos são tratados como fazendo parte de um mesmo fenômeno, e sua distinção baseiase em considerações teóricas: enquanto significados referem-se a narrativas socialmente disponíveis e socializadas sobre um determinado tópico ou objeto, sentidos relacionam-se a processos de apropriação/ produção singular dos significados (Bendassolli \& Gondim, 2014; Tolfo, Coutinho, Baasch, \& Gugnier, 2011; Vygotski, 1993a, 1993b). A compreensão de ambos, mediados pela atividade, constitui o processo de significação. Na sequência, detalhamos cada componente desse trinômio.

\section{Sentidos e significados}

Em termos gerais, a discussão sobre sentidos e significados refere-se à mediação, pela linguagem, entre consciência e realidade, sujeito e objeto, subjetividade e intersubjetividade. Na psicologia, Vygotski (1993a, 1993b) discute essa questão ao relacionar pensamento e linguagem. Segundo o autor, para que uma pessoa domine a função de comunicação, é preciso que ela domine igualmente o significado das palavras, aqui entendido como generalização do signo. Significado faz referência a classes de objetos abarcados pela palavra. Refere-se a cristalizações provisórias que se formam, na cultura, sendo apropriadas pelas pessoas em processos singulares de produção de sentidos. Estes, portanto, fazem referência a processos psicológicos mais fundamentais, pelos quais o sujeito ressignifica aquilo que recebe pela linguagem (e que também atualiza/ produz pela atividade), dando-lhe uma conotação própria, notadamente afetiva (Namura, 2004; Smolka, 2004; Zanella, Reis, Titon, \& Dassoler, 2007).

Em sua obra, Vygotsky (1993a) nos leva a pensar na existência de uma relação dialética entre sentido-significado, um tensionamentos entre forças dispersadoras e estabilizadoras de sentidos. Tal dialética pode ser apreendida a partir 
dos tensionamentos intrínsecos à própria função comunicativa da linguagem. Isso porque a linguagem contém os elementos impessoais e transpessoais (não estrito a um grupo ou coletivo, mas extensível à cultura como um todo), articulados em narrativas socialmente compartilhadas e que estabilizam, dentro de um determinado contexto, formas de vida, gêneros (Clot, 2008) ou repertórios a compor os processos de socialização. Mas é igualmente pela linguagem que o sujeito se singulariza. Mediante um duplo movimento, de internalização e externalização, ele ao mesmo tempo se apropria daquelas narrativas, as ressignifica e então produz novas articulações, novos significados, compartilhando-os pela linguagem. Os referidos tensionamentos fazem parte dos processos de subjetivação (apropriação dos significados/ internalização) e objetivação (compartilhamento do sentido/externalização) discutidos por Vygotski (1993a, 1993b).

Emerge dessa definição de sentidos-significados uma compreensão sobre a função intersubjetiva da linguagem, pois o processo de apropriação de significados ocorre em um contexto de interação interpessoal, bem como transpessoal, impessoal (regras/ normas) e objetivo (ferramentas, produto gerado/ transformado pela atividade). Isso nos permite pensar que o horizonte dos significados-sentidos é a cultura e suas instituições. Podemos dizer que os significados são reproduções mantidas pelas instituições, compreendidas em sua acepção mais ampla, como instituições de sentido (Descombes, 1996).

No que diz respeito aos sentidos, sua produção implica na consideração de mecanismos psicológicos do nível individual, como a criatividade, a imaginação, a memória, os agenciamentos de estados afetivos e cognitivos, entre outros processos envolvidos na utilização da linguagem (Vygotski, 1993b). Todavia, importante enfatizar que isso não se dá em isolamento: o sujeito é singular, mas está situado nos tensionamentos objetividade/subjetividade da linguagem - esta última um fenômeno essencialmente social. A produção de sentidos não se dá, portanto, de modo "desencarnado" da realidade material, e é neste ponto que introduzimos o terceiro elemento ilustrado na Figura 1, a atividade.

\section{Atividade de trabalho}

A discussão sobre a atividade, no interior da perspectiva aberta por Vygotski, ganha destaque, em grande parte, devido à obra de Leontiev (1978) e, depois dele, dos autores que compõem as teorias da atividade (e.g., Bedny \& Karwowski, 2007; Clot, 1999, 2008; Wertsch, 1981). Embora mantendo a ideia básica de Vygotski (1993a, 1993b) sobre o processo de produção de sentidos e significados pela mediação da linguagem, as teorias da atividade aprofundam na questão da mediação pelas relações sociais implicadas no trabalho, bem como a mediação por ferramentas, tais como máquinas, equipamentos, tecnologia, e demais recursos do ambiente/contexto, incluindo a cultura (Cole, Engeström, \& Vasquez, 1997; Valsiner, 2007). Tal perspectiva encontra uma síntese nos estudos de Engeström $(1999,2001)$. A Figura 2 ilustra seu modelo de atividade, utilizado como referência neste artigo. Em que medida se dinamiza, por esse sistema de atividade, o processo de significação?

Figura 2. Sistema de atividade proposto por Engeström (2001, p. 135 - adaptado)

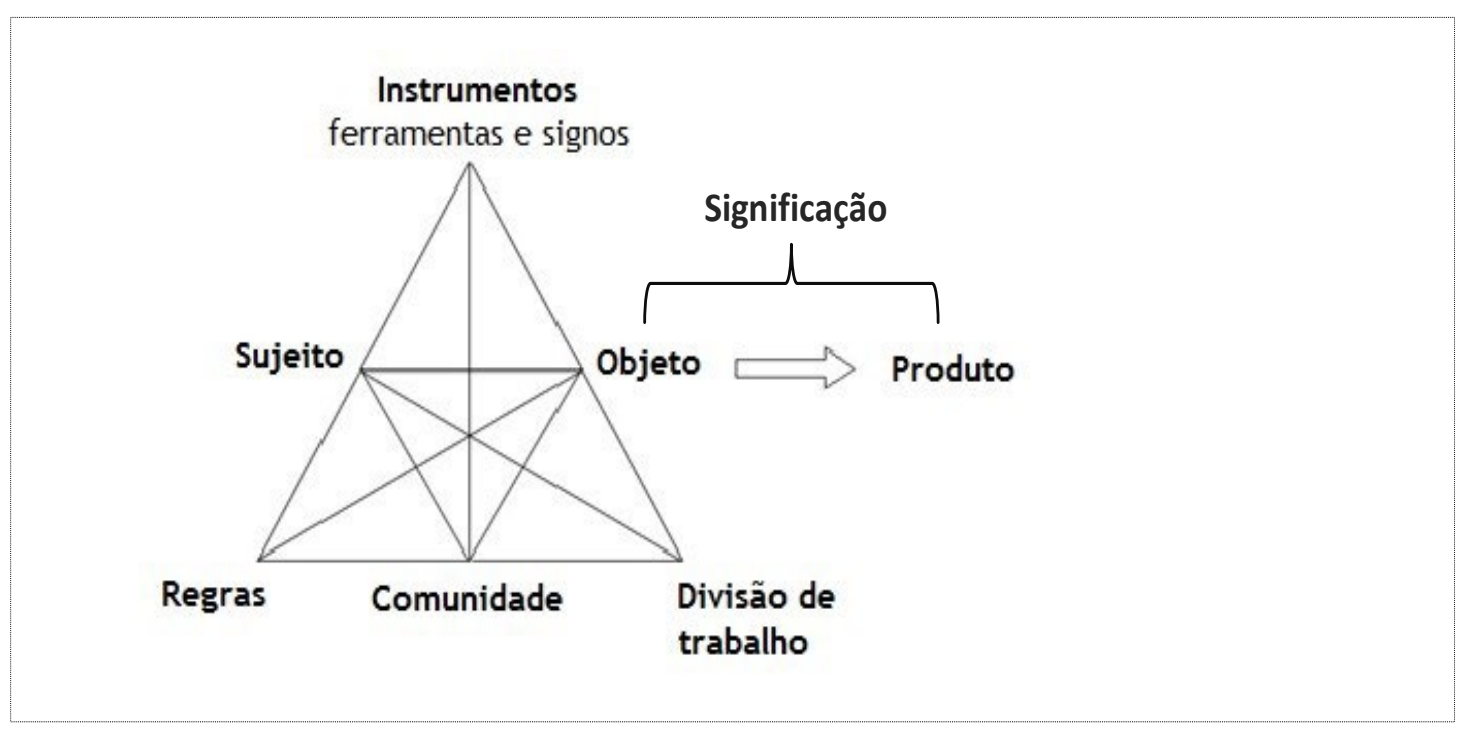


Primeiramente, o sujeito tem à sua disposição (ao mesmo tempo que produz, dialeticamente), no contexto semiótico da atividade, os significados provenientes das regras de seu ofício; os valores e saberes armazenados e transmitidos por sua comunidade de pertencimento, incluindo pares (ou gênero profissional - Clot, 2008); os significados implicados na forma de organizar/ dividir o trabalho; e também o próprio significado materializado nos instrumentos de trabalho, derivados de um longo processo histórico de aperfeiçoamento técnico, passando de geração a geração, como memória de atividades passadas (Leontiev, 1978). Esses significados, além de comporem o processo de comunicação, também funcionam como um dos recursos para a ação, para o agir do sujeito. Trata-se, aqui, do significado-em-uso, no aspecto performativo da própria linguagem.

Em segundo lugar, a atividade exige do sujeito, a todo instante, planejamento da ação, organização dessa mesma ação de modo a antever consequências sobre o contexto, sobre o objeto da atividade e, principalmente, sobre o produto a ser gerado. No caso da atividade de trabalho, isso depende de uma constatação ontológica mais ampla relacionada ao próprio trabalho: o fato de ele ser uma atividade intencional, direcionada a outra pessoa (pares, comunidade, a atividade do outro); ao próprio sujeito, seus projetos pessoais, suas expectativas e mobilizações na atividade, em suma, seu sentido; e ao objeto da atividade, a relação desta com a realidade imediata, dentro de um contexto de valorização (econômica, social, cultural). Portanto, a atividade é, em larga medida, consciente, não automática - e é por isso que o sujeito pode, se questionado, falar sobre ela.

Diante do exposto, pode-se dizer que a atividade possui duas dimensões: a objetiva, onde ocorre o processo de produção de objetos/serviços (inclusive em termos de eficiência e maestria-Clot, 2008), e subjetiva, com reverberações no nível do sujeito, naquilo que a atividade lhe mobiliza, na forma como se apropria dos vários significados envolvidos e produz novos sentidos. Isto é, a atividade participa, ativamente, do processo de externalização e internalização. É ao colocar-se em atividade que o sujeito produz significações, pois, entre outros aspectos, ele antecipa, ele idealiza, na forma de plano, o resultado de seu trabalho, integrando aspectos objetivos e subjetivos. É por isso que, na Figura 2, o processo de significação se demarca no momento em que a atividade é questionada sobre seu porquê, seu motivo ou necessidade (Leontiev, 1978), tanto de um ponto de vista coletivo como pessoal.

Em síntese, podemos definir o processo de significação como a relação dialética, marcada por tensionamentos, entre sentido e significado na constituição da pessoa em sua interação com a atividade, em um determinado contexto, no interjogo de sujeição (aos significados) e pessoalização (pelos sentidos) (Bendassolli \& Gondim, 2014; Clot, 1999, 2008). Ao passo que o sentido é ilimitado, instável e dinâmico, os significados são estáveis, categoriais, refletindo o repertório cultural acumulado por um determinado grupo, instruindo seus membros acerca do modo de operar sobre a realidade (Vygotski, 1993a, 1993b). Por sua vez, a atividade interpõe-se como mediação entre sentidos e significados, pois permite ao sujeito sua inscrição em um contexto concreto, pelo qual ele elabora sentidos (atravessados pela dinâmica da cultura, das relações e da sua própria história pessoal) em reação, dialógica, aos significados disponibilizados e utilizados como recursos para ação no trabalho. Tendo em vista a importância do contexto, na própria seção nos detemos em alguns aspectos sócio-históricos e econômicos da atividade realizada na informalidade - outro componente-chave da Figura 1.

\section{Informalidade: aspectos do contexto socioeconômico}

O conceito de informalidade é relativamente recente no meio acadêmico e governamental. Ele data do início da década de 1970, quando Hart (1973), ao pesquisar sobre o mercado de trabalho em Gana/ Quênia, identificou formas de trabalho que escapavam ao padrão eurocidental: o trabalho assalariado fordista (Busso, 2010; Costa, 2010).

De um construto eminentemente descritivo, a informalidade passou a congregar uma miríade de teorias explicativas. As primeiras delas foram as desenvolvimentistas, hegemônicas nos organismos internacionais, como na Organização Internacional do Trabalho (OIT) e na Comissão Econômica para a América Latina e o Caribe (CEPAL). Ambas pressupunham uma cisão entre os setores formal e informal, determinada pelo padrão de desenvolvimento econômico adotado por cada país, e previam uma absorção do setor informal pelo formal (Busso, 2010). Com os sucessivos questionamentos desses prognósticos, outras frentes teóricas ganharam espaço.

Uma dessas novas perspectivas, com inspiração marxista, situava a informalidade no processo de acumulação capitalista, e não como uma anomalia desse modo de produção (Costa, 2010). Em outra abordagem, de viés neoliberal, a informalidade era tomada como uma nova institucionalização do trabalho que prescindia do Estado, sendo a saída para a crise social da década de 1980 (Busso, 2010). Uma terceira 
frente de teorias herda diversos debates empreendidos nos períodos anteriores, mas tem como principal característica a consideração sobre o dinamismo da informalidade, e sua extensa multiplicação - incluindo a informalidade na própria formalidade (Antunes, 2011; Busso, 2010; Cardoso, 2013; Costa, 2010; Krein \& Proni, 2010; Tavares, 2010), ou ainda o conceito de "nova informalidade" (Noronha, 2003).

Situando-se na terceira frente teórica sobre informalidade, este artigo define informalidade como um processo com dois marcadores: o assalariamento sem carteira, e o trabalho autônomo e de sobrevivência (Cacciamali, 2000). A eles soma-se um terceiro grupo, os trabalhadores informais clássicos (Alves \& Tavares, 2006), que corresponde aos trabalhadores com um mínimo de conhecimento e meios de trabalho, atuando no setor de serviços, como costureiras, pedreiros e jardineiros; outros integrados temporariamente na produção e remunerados por trabalho ou peça, como os carregadores e carroceiros; e os que, enquanto procuram um emprego, realizam bicos de várias naturezas. Por sua vez, tais atividades não são exercidas em um cenário paralelo às unidades capitalistas tradicionais, havendo uma relação estreita entre elas (Antunes, 2011; Cacciamali, 2000; Tavares, 2010).

A raiz histórica da informalidade, longe de ser o resultado de um "desvio" no desenvolvimento dos países periféricos, parece refletir o processo de mundialização do capitalismo, sendo a sua compreensão perpassada pela reestruturação produtiva ocorrida no pós-1970, pela internacionalização e expansão do mercado financeiro, pelo aprofundamento da abertura e da internacionalização comercial, e pela desregulamentação dos mercados (Cacciamali, 2000). Ainda que seja um fenômeno presente, massivamente, nos países periféricos, incluindo o Brasil, observase nas últimas décadas sua proliferação também nos países centrais (Cunha, 2006).

A informalidade coloca aos trabalhadores um contexto socioeconômico peculiar no processo de venda da sua força de trabalho e, portanto, na forma de exercer a sua atividade, havendo:

1. Ausência de uma instituição social que regule, diretamente, as relações de trabalho dentro da informalidade, influenciando na forma como se contrata a força de trabalho, sendo característico a elaboração individualizada de acordos, lastreados não em uma legislação existente, mas em laços de confiança (Cardoso, 2013);

2. Afastamento dos trabalhadores informais, seja em qual grupo se localiza, das conquistas históricas dos direitos trabalhistas (Costa, 2010);
3. Diferenciação em relação ao trabalho exercido no padrão taylorista-fordista (modelo costumeiramente analisado pela psicologia), uma vez que há na informalidade (com algumas poucas exceções) uso escasso de tecnologia, bem como atividades que exigem baixa qualificação formal (Dias et al., 2011);

4. Foco na obtenção de renda (subsistência), e não de capital, com uma divisão pouco clara entre as funções de capitalista e trabalhador, na medida em que o próprio proprietário dos empreendimentos também dispende a sua força de trabalho no processo produtivo (Cacciamali, 2000; Krein \& Proni, 2010).

Conforme implícito no modelo teórico mostrado na Figura 1, esse contexto pode levar a processos de significações específicos, embora articulados com o setor formal, visto que não haveria, como se argumentou, uma cisão entre ambos, mas diferenciações e pontos de interligação. Essas situações específicas, por seu turno, engendram desafios e possibilidades para o estudo da informalidade pelo viés dos processos de significação.

\section{Desafios e possibilidades de pesquisa}

Nesta seção nosso propósito é integrar, numa síntese, os dois conjuntos de ideias exibidos anteriormente, os quais compõem o modelo apresentado na Figura 1. Para nos orientar, retomamos as três hipóteses colocadas na introdução.

A primeira hipótese dizia respeito à possibilidade de o estudo do trabalho informal, pelo ângulo dos processos de significação, permitir o acesso a tensões entre formal/informal. De fato, como visto na seção anterior, o trabalho formal, embora não abarcando, historicamente, a totalidade do coletivo de trabalhadores no Brasil, consiste de um arranjo social em que se concentram direitos, garantias e contrapartidas conquistadas pelos trabalhadores ao longo de suas diversas lutas no interior do capitalismo. Em geral, é também no trabalho formal que se verifica maior densidade tecnológica, complexidade de conhecimentos formais e valorização do trabalho, além de um padrão produtivo mais elevado.

A informalidade não nasce como universo paralelo ao trabalho formal. $\mathrm{O}$ fenômeno da informalidade responde, em parte, pela dinâmica do próprio capitalismo, quer no sentido de redução de custos (como veio a se dar com as terceirizações e flexibilizações), quer no sentido de mudanças mais profundas nos contratos de trabalho, transferindo aos trabalhadores a responsabilidade pela gestão de seu 
cotidiano, em regime de assalariamento sem carteira ou autônomo. É emblemática, a esse propósito, a valorização da figura do empreendedor, da pessoa que se faz sozinha, num contexto de individualização, tomada de risco e ilusão de igualdade de condições (Malaguti, 2000; Noronha, 2003).

Se a informalidade não nasce e se mantém como um universo paralelo no plano objetivo (pois o sistema produtivo formal mantém relações estratégicas com ela), ela decerto também não é "autônoma" no plano subjetivo. É aqui que reside um primeiro caminho de pesquisa: a exploração dos significados atribuídos à informalidade pode ser uma via para se acessar os conteúdos simbólicos/culturais produzidos pelo/no capitalismo em relação à informalidade. Isso tem como pressuposto que os significados, como produções/ narrativas coletivas, relativamente estabilizadas e disseminadas, não são isentos de poder, ocupando uma função no ordenamento sócio-cultural. A análise dos significados, a nosso ver, perde em força crítica se se restringir ao nível puramente descritivo, dado que isso não captaria os dispositivos de poder e os usos dos discursos/narrativas produzidos sobre a informalidade, tendo em vista certos propósitos nem sempre explicitados.

Assim, os significados produzidos institucionalmente sobre a informalidade podem, por exemplo, apresentar esta última como uma espécie de "paraíso" para a autoiniciativa, a independência e o empreendedorismo, algo captado por Malaguti (2000), quando constata a existência de um incentivo a formas autônomas (e, eventualmente, informais) de trabalho, em parte estimuladas pela mídia de massa e pelos organismos governamentais, valorizando tais modalidades de trabalho.

Contudo, os significados produzidos sobre a informalidade podem, ao contrário, ser depreciativos em relação a ela: a informalidade como "negativo do emprego formal" (Sato, 2011). Isso poderia fazer as pessoas que vivem na informalidade nutrirem o desejo de sair dessa condição, vendo-a como provisória, ou então se sentirem diminuídas e socialmente inferiorizadas. Isso já foi, inclusive, objeto de alguns estudos (e.g., Busso, 2007; Cardoso, 2013; Druck, 2013; Gómez, 2011; Tavares, 2010), embora assumindo outras perspectivas teóricas que não a proposta no presente artigo.

Outro modo de apreender as tensões formal/ informal ocorre quando consideramos a relação dos significados com as "instituições de sentido" (Descombes, 1998). Em hipótese, no trabalho formal o conteúdo dos significados é fornecido, pelo menos em parte, pela organização, como também assentado em narrativas institucionais relativamente lineares. Por exemplo, em termos do significado de certas ocupações/funções (gerente, executivo, médico, advogado, etc.), do que esperar do futuro/progressão pessoal na carreira, e de competências exigidas e desenvolvimento profissional.

Já no trabalho informal, as narrativas podem ser menos lineares, pois ali se estar diante de uma ampla morfologia de atividades, ocupações, funções, muitas das quais hierarquizadas como de baixo status social e mesmo precárias (Antunes, 2011; Druck, 2013; Malaguti, 2000; Tavares, 2010). Assim, o trabalho informal pode colocar desafios ou obstáculos a processos lineares de construção de sentidos e significados, processos esses referendados pela macronarrativa do emprego formal.

A segunda hipótese colocada no início deste artigo refere-se à possibilidade de a investigação dos processos de significação permitir o trânsito por distintos níveis de análise. De fato, significados referem-se a narrativas coletivas, à generalização do signo no processo de comunicação. Sentidos referemse à apropriação dos significados pelo sujeito, mediada pela atividade. Em psicologia, diversos estudos sobre significados do trabalho são realizados com base em premissas cognitivistas (Tolfo et al., 2011). Nesses casos, em geral são utilizados questionários padronizados para captar cognições sociais acerca do trabalho (significados).

Porém, há uma outra frente de estudos que, inspirados em perspectivas qualitativas, priorizam a exploração da singularidade, dos sentidos - embora não necessariamente na acepção aqui proposta. No primeiro caso, a singularidade é minimizada; no segundo, mesmo que haja exceções, nota-se a baixa ênfase de pesquisadores em fazer a discussão entre níveis, isto é, de propiciar o trânsito analítico entre o individual e o coletivo, detendo-se nas narrativas em sua faceta mais singular (Bendassolli \& Gondim, 2014).

Essa suposta rigidez no trânsito entre níveis de análise traz um possível problema quando se trata do trabalho informal. Se o foco é, prioritariamente, no nível dos significados, o pesquisador pode adotar, conscientemente ou não, uma postura generalizante - por exemplo, inferindo que, na informalidade, as pessoas apreenderiam ou produziriam significados a partir de dimensões relacionadas ao emprego formal, implicitamente assumido como a forma de trabalho mais "legítima". Isso pode se expressar nas estratégias de elaboração dos instrumentos de coleta de dados, quando, ao não discutir potenciais diferenciações entre formal/informal, se faria a transposição de conceitos de um campo a outro, talvez no espírito de 
que "tudo é trabalho". Ademais, o foco exclusivo nos significados, desconectados dos sentidos, traz o risco de não se reconhecer a heterogeneidade de modos de trabalhar e produzir significações na informalidade.

Por seu turno, o foco prioritário nos sentidos pode nos levar a outras dificuldades. Uma deles é de considerar a informalidade como algo natural, endossando certos discursos correntes que buscam valorizá-la, ao mesmo tempo que mascarando os processos históricos que estiveram (e ainda estão) na base de sua existência. Esse é um risco potencial em pesquisas que tentem a privilegiar os aspectos subjetivos relacionados às vivências das pessoas.

Nesses casos, exploram-se estratégias individuais de enfrentamento, questões de sofrimento ligadas à atividade informal, trajetórias pessoais, entre outros aspectos da experiência subjetiva. Ora, se o sujeito "vê" sentido na sua condição laboral, isso seria motivo para endossar a informalidade como forma "legítima" de estar no mundo do trabalho? A resposta a tal questão depende, essencialmente, do conceito de informalidade adotado, consciente ou não, pelo pesquisador. Bem como de seu conceito de sentido. Assim, "encontrar" (ou não) sentido no trabalho informal é uma questão com conotações sócio-políticas importantes.

É importante frisar que não se trata de negar o valor dessa abordagem de viés mais psicologizante. $\mathrm{O}$ argumento que se coloca é o de que sentidos são inextricavelmente ligados aos significados, ambos mediados pela atividade, e situados em um contexto material e sócio-político concreto, cuja compreensão convém estar explicitada nos modelos de pesquisa.

Para desenvolver melhor esse último argumento, passamos à ultima hipótese colocada neste artigo, referente às possibilidades abertas pela introdução da atividade na investigação dos processos de significação na informalidade. Tal introdução, a nosso ver, contornaria ou atenuaria uma análise de tipo eminentemente cognitivista, de recorte individual (individualismo metodológico), sobre sentidos e significados. Também permitiria um olhar mais atento à amplitude de modos de "estar em atividade" na informalidade, resguardando, desse modo, a heterogeneidade já apontada em relação a esse contexto.

\section{Atividade, sentido, informalidade}

A utilização do modelo de atividade exibido na Figura 2 possibilita ao pesquisador explorar as diversas estratégias com que as pessoas organizam sua atividade, respondem a questões pessoais, interpessoais, impessoais e transpessoais - a relação mais ampla com a cultura de trabalho, por exemplo. De um lado, é importante dizer que a atividade, tal como apresentada aqui, não se restringe pela distinção formal/informal.

Assim, no nível da atividade em si, esta faz a mediação do sujeito com sua realidade imediata (independentemente se formal/informal), permitindo a emergência do processo de significação tal como discutido neste artigo, com sua face objetiva (externalização) e subjetiva (internalização). Propicia a constituição do sujeito ao "abri-lo" às possibilidades para a renovação contínua dos significados. Nesse nível micro da atividade se poderia também investigar os impedimentos a ela colocados (Clot, 1999, 2008), visando à sua superação/problematização; a relação dos trabalhadores com as regras do ofício; os formatos de divisão e organização do trabalho e suas consequências; a constituição de gêneros de atividade, no modo de subculturas de ofício - em suma, os componentes da Figura 2.

Mas, em um nível mais macro, a atividade é atividade de trabalho. E é nesse nível que compete ao modelo de pesquisa dialogar com as forças que instituem e moldam o trabalho informal (como modalidade de organização social). $\mathrm{O}$ trabalho seria, pois, mais amplo que a atividade, embora seja por meio desta última que aquele se realize concretamente.

Como consequência da afirmação anterior, cumpre enfatizarmos que a análise da atividade, à semelhança do que se faz em certas perspectivas ergonômicas, não corresponde ao que defendemos aqui. Primeiro, pois a atividade é mediação, por meio da qual se circulam e se produzem sentidos e significados, bens e serviços - não apenas movimentos do corpo ou de interação com coisas (objetos, ferramentas); segundo, pois a atividade se inscreve num conjunto social mais amplo. Neste caso, é preciso reconhecer que a informalidade, pelo menos se vista como existindo devido a necessidades ou estratégias do sistema produtivo em seu processo histórico, coloca desafios importantes ao que entendemos por um "trabalho decente" ou, sobretudo, por uma sociedade justa.

Adicionalmente, a consideração do processo de significação em sua totalidade nos leva a repensar a questão colocada poucos parágrafos acima: qual a implicação de uma pessoa "encontrar" sentido no trabalho? Por definição, qualquer atividade, independentemente de ser formal ou informal, articula, necessariamente, sentidos e significados. Teoricamente, o trabalho não "tem" ou "deixa de ter" significação. O significado e o sentido não são coisas "contidas" no trabalho, como se este fosse um vaso. 
A análise da significação permite ao pesquisador compreender, junto com o trabalhador, o processo do trabalho real, em sua dinâmica e processualidade, ao mesmo tempo subjetiva e objetiva. E dado que a atividade (e o trabalho) não se referem apenas à produção de coisas, mas também de sujeitos e da própria cultura, sua análise possibilita, tanto para o pesquisador como para o trabalhador, um movimento de crítica, transformação e, na medida do possível, emancipação.

É neste ponto que a perspectiva do processo de significação pode contribuir para o questionamento, em alguma medida, da informalidade, fazendo-o do interior desta última, no núcleo mesmo em que se encontra o sujeito e seu trabalho/atividade. Se, de um lado, não se trata de "empoderar" esse sujeito para suportar sua situação, de outro, também não se trata de negar ao trabalho informal a possibilidade de permitir significação. $\mathrm{O}$ aspecto decisivo é em que medida tal significação pode ser apropriada como vetor de transformação para o próprio sujeito, de sua condição.

Por exemplo, em que medida o componente "comunidade" apresentado na Figura 2 não poderia ser trabalhado, fazendo com que os trabalhadores "vejam sentido" na constituição de coletivos de trabalho? Coletivos que, numa primeira acepção, referem-se às culturas de ofício ou gêneros profissionais (Clot, 2008), mas que também representam um vetor político de organização e defesa de interesses comuns. Essa seria uma forma de contornar um aspecto aludido anteriormente, sobre a suposta "individualização" que se observa na informalidade, e o esvaziamento/ enfraquecimento do coletivo. Questões de sentido podem estar envolvidas nesse quadro. Os outros componentes da Figura 2 poderiam ensejar discussões similares por parte dos pesquisadores interessados no tema.

\section{Considerações finais}

O objetivo do presente artigo foi discutir as potencialidades de analisarmos e pesquisarmos a informalidade da perspectiva dos processos de significação. Desenvolvemos o argumento de que tal processo é composto por três componentes indissociáveis e dialeticamente articulados: significados, sentidos e atividade.

A natureza dialética dessa relação se afirma no fato de que o sujeito se constitui na interação com o outro, imerso na cultura e na processualidade histórica. Portanto, há um interjogo contínuo entre singularidade (a linguagem interna, no dizer de Vygotsky, 1993a), com suas vicissitudes, dinamismos, experiências e vivências, e os aspectos coletivos dessas mesmas experiências, nos quais podemos identificar zonas de relativa estabilidade e ordenamento social (presentes na linguagem externa, na interação, nos significados estabilizados). Apontamos que a investigação do trabalho informal pode se beneficiar da articulação dialética entre sentido-significado, das tensões entre forças dispersadoras e estabilizantes dos sentidos em sua contínua reanimação pela atividade concreta.

Em síntese, algumas das principais potencialidades analíticas do modelo aqui proposto envolvem, primeiro, a possibilidade de superação de certa dicotomia potencialmente presente nos estudos dos processos de significação: ora centrados sobretudo na dimensão do significado (estável, coletivo), ora na dos sentidos (qualitativa, dinâmica, idiossincrásica). Segundo, na importância de se recuperar a dimensão do "real do trabalho", seja ele informal ou formal. No caso da informalidade, a explicitação do trabalho real pode revelar as estratégias cotidianas do fazer, do "se virar", da lida concreta com desafios impostos pela atividade, mas também por uma organização social excludente, indiferente, levando à invisibilidade dos trabalhadores informais.

Por fim, o modelo proposto na Figura 1 visa, especialmente, ao questionamento das implicações ético-políticas associadas à produção/reprodução de sentidos-significados: se, de um lado, é compromisso do psicólogo do trabalho a defesa de condições para que a atividade laboral cumpra seu papel de constituinte do sujeito, por outro, ele deve, permanentemente, se questionar sobre os significados socialmente produzidos e impostos à atividade dos outros, e sobre o quanto tais significados estão a serviço de relações de dominação ou de emancipação dos trabalhadores.

\section{Referências}

Alves, M. A. \& Tavares, M. A. (2006). A dupla face da informalidade do trabalho: "autonomia" ou precarização. In R. Antunes (Org.), Riqueza e miséria do trabalho no Brasil (pp. 387-446). São Paulo: Boitempo.

Antunes, R. (2011). Os modos de ser da informalidade: rumo a uma nova era da precarização estrutural do trabalho? Serviço Social \& Sociedade, 107, 405-419

Bedny, G. \& Karwowski, W. (2007). A systemic-structural theory of activity. Florida: Taylor \& Francis Group.

Bendassolli, P. F. (2012). Psicologia do trabalho como psicologia da ação: o aporte das teorias da atividade. Psico, 43, 341-349.

Bendassolli, P. F. \& Borges-Andrade, J. E. (2011). Significado do trabalho nas indústrias criativas. Revista de Administração de Empresas, 51(2), 143-159. 
Bendassolli, P. F. \& Gondim, S. M. (2014). Significados, sentidos e função psicológica do trabalho. Avances em Psicologia Latinoamericana, 32, 131-147

Borges, L. O. (1997). Os atributos e a medida do significado do trabalho. Psicologia: Teoria e Pesquisa, 13(2), 211-221.

Busso, M. (2007). "Trabajadores informales en argentina: ¿de la construcción de identidades colectivas a la constitución de organizaciones?" Tese de Doutoramento, Universidade de Buenos Aires/Université de Provence. Publicación disponible en HAL-SHS http://halshs.archives-ouvertes.fr/

Busso, M. (2010). Trabajo informal: una categoría en tensión(es). In M. Busso \& P. Pérez (Coords.), La corrosión del trabajo: estudios sobre informalidad y precariedad laboral (pp. 121135). Buenos Aires: Miño y Dávila.

Cacciamali, M. C. (2000). Globalização e processo de informalidade. Economia e Sociedade, 14, 153-174.

Cardoso, A. (2013). Ensaios de sociologia do mercado de trabalho brasileiro. Rio de Janeiro: FGV Editora.

Clot, Y. (1999). La fonction psychologique du travail. Paris: PUF.

Clot, Y. (2008). Travail et pouvoir d'agir. Paris: PUF.

Cole, M., Engeström, Y., \& Vasquez, O. A. (1997). Mind, culture, and activity. Cambridge: Cambridge University Press.

Costa, M. S. (2010). Trabalho informal: um problema estrutural básico no entendimento das desigualdades na sociedade brasileira. Cadernos CRH, 23(58), 171-190.

Cunha, M. I. P. (2006). Formalidade e informalidade: questões e perspectivas. Etnográfica, 10(2), 219-231.

Cunha, T. B. \& Vieira, S. B. (2009). Entre o bordado e a renda. Psicologia: Ciência e Profissão, 29(2), 258-275.

Descombes, V. (1996). Les institutions du sens. Paris: Minuit.

Dias, E. C., Oliveira, R. P., Machado, J. H., Minayo-Gomez, C., Perez, M. A. G., Hoefel, M. G. L., \& Santana,V. S. (2011). Employment conditions and health inequities: a case study of Brazil. Cadernos de Saúde Pública, 27(12), 2452-2460.

Druck, G. (2013). A precarização social do trabalho no Brasil. In R. Antunes (Org.), Riqueza e miséria do trabalho no Brasil II (pp. 55-74). São Paulo: Boitempo

Engeström, Y. (1999). Activity theory and individual and social transformation. In Y. Engeström, R. Miettinen, \& R. L. Punamäki (Eds.), Perspectives on activity theory (pp. 1938). Cambridge: Cambridge University Press.

Engeström, Y. (2001). Expansive learning at work: toward and activity theoretical reconceptualization. Journal of Education and Work, 14(1), 133-156.

Fernandes, L. \& Araújo, T. (2012). Trabalhos de margem no centro da urbe: o arrumador de automóveis. Etnográfica, 16(1), 5-30.

Fernandes, F. S., Gonçalves, C. M., \& Oliveira, P. J. (2012). Adaptação e validação da Escala de Significados Atribuídos ao Trabalho - ESAT. Revista Brasileira de Orientação Profissional, 13(2), 183-195.

Gómez, M. C. P. (2011). Significados asociados al futuro laboral: entre la formalidad y la informalidad. Pensamiento psicológico, 9(16), 107-124.

Goulart, P. M. (2009). O significado do trabalho: delimitações teóricas (1955-2006). Cadernos de Psicologia Social do Trabalho, 12(1), 47-55.

Hart, K. (1973). Informal income opportunities and urban employment in Ghana. Journal of Modern African Studies, 11(1), 61-89.
Instituto Brasileiro de Geografia e Estatísticas - IGBE. (2014). Indicadores IBGE: pesquisa mensal de emprego, março de 2014. Brasília, DF: Autor.

Krein, J. D. \& Proni, M. W. (2010). Economia informal. Brasília, DF: OIT Brasil.

Leontiev, A. N. (1978). Activity, consciousness, and personality. Englewood Cliffs, NJ: Prentice-Hall.

Lourenço, C. D. S., Ferreira, P. A., \& Brito, M. J. (2013). O significado do trabalho para uma executiva. Organizações em Contexto, 17(9), 247-279.

Malaguti, M. L. (2000). Crítica à razão informal: a imaterialidade do salariado. São Paulo: Boitempo.

Morin, E. (2001). Os sentidos do trabalho. Revista de Administração de Empresas, 41(3), 8-19.

Morin, E. (2007). Sens du travail, santé mentale au travail et engagement organisationnel. Cahier de Recherche, 543, 99193.

Meaning of Work International Research Team - MOW. (1987). The meaning of working. London: Academic Press.

Morse, N. C. \& Weiss, R. C. (1955). The function and meaning of work and the job. American Sociological Review, 20(2), 191-198.

Namura, M. R. (2004). Por que Vygotski se centra no sentido: uma breve incursão pela história do sentido na psicologia. Psicologia Educacional, 19, 91-117.

Noronha, E. G. (2003). "Informal”, ilegal, injusto: percepções do mercado de trabalho no Brasil. Revista Brasileira de Ciências Sociais, 18(53), 111-129.

Oliveira, M. C. L. \& Silveira, S. B. (2012). O(s) sentido(s) do trabalho na contemporaneidade. Veredas, 16(1), 149-165.

Sato, L. (2009). Visitando a feira livre: notas sobre sua oganização e trabalho. Mnemosine, 5, 227-248.

Sato, L. (2011). Psicologia e trabalho: focalizando as 'profissões ignoradas'. In B. Medrado \& W. Galindo (Orgs.), Psicologias social e seus movimentos: 30 anos de ABRAPSO (pp. 233250). Recife: Editora Universitária da UFPE.

Sato, L. (2013). Recuperando o tempo perdido: a psicologia e o trabalho não regulado. Cadernos de Psicologia Social do Trabalho, 16(n. spe.), 99-110.

Smolka, A. L. B. (2004). Sobre significação e sentido: uma contribuição à proposta de redes de significação. In M. C. Rossetti-Ferreira, K. S. Amorin, \& A. P. S. Silva (Orgs.), Redes de significações: alguns conceitos básicos (pp. 3549). Porto Alegre: Artmed.

Spink, P. K. (2009). Micro cadeias produtivas e a nanoeconomia: repensando o trabalho decente. Cadernos de Psicologia Social do Trabalho, 12(2), 227-241.

Tavares, M. A. (2010). O trabalho informal e suas funções sociais. Revista Praia Vermelha, 20(1), 21-36.

Tolfo, S. R., Coutinho, M. C., Baasch, D., \& Cugnier, J. S. (2011). Sentidos y significados del trabajo: un análisis con base en diferentes perspectivas teórico-epistemológicas en Psicología. Universitas Psychologica, 10(1), 175-188.

Tolfo, S. R. \& Piccinini, V. (2007). Sentidos e significados do trabalho: explorando conceitos, variáveis e estudos empíricos brasileiros. Psicologia \& Sociedade, 19(n. spe.), 38-46.

Valsiner, J. (2007). Culture in minds and societies. Londres: Sage.

Vigotski, L. S. (1993a). Pensamiento e lenguaje. In Obras escogidas (Vol. 2, pp. 9-349). Madrid: Visor. (Original publicado em 1934) 
Vygotski, L. S. (1993b). Historia del desarrollo de las funciones psíquicas superiores. In Obras escogidas (Vol. 3, pp. 11340). (Original publicado em 1931)

Wertsch, J. (Ed.). (1981). Concept of activity in soviet psychology. New York: M. E. Sharpe.

Zanella, A. V., Reis, A. C., Titon, A. P., \& Dassoler, T. R. (2007). Questões de método em textos de Vygotski. Psicologia \& Sociedade, 19(2), 25-33.

\section{Agradecimento}

Conselho Nacional de Desenvolvimento Científico e Tecnológico - CNPq, Edital MCTI/CNPQ/ MEC/CAPES N ${ }^{\circ}$ 22/2014, Processo 471313/2014-9.

Submissão em: 26/06/2014

Revisão em: 18/11/ 2014

Aceite em: 19/12/2014
Pedro F. Bendassolli é psicólogo. Doutor em Psicologia Social do Trabalho (USP, 2006). Realizou estágios pósdoutorais na Université PARIS IX (Centre de Recherche Management \& Organisation, 2009) e no Instituto de Psicologia da UNB (Departamento de Psicologia Social e do Trabalho, 2012). Professor do Departamento de Psicologia da UFRN e de seu Programa de Pós-graduação. Desenvolve suas pesquisas no Grupo de Estudos e Pesquisas sobre o Trabalho - GEPET (http://www.gepet. org). Endereço para correspondência: UFRN - CCHLA. Pós-Graduação em Psicologia. Campus Universitário. Lagoa Nova. Natal/RN, Brasil. CEP 59078-970

E-mail: pbendassolli@gmail.com

Fellipe Coelho-Lima é doutorando (2013) no Programa de Pós-Graduação em Psicologia da Universidade Federal do Rio Grande do Norte (UFRN). Possui graduação (2010) e mestrado (2013) em Psicologia pela mesma instituição. É membro do Grupo de Estudos e Pesquisa sobre o Trabalho (GEPET/UFRN), do Grupo de Pesquisas Marxismo \& Educação (GPM\&E/UFRN). E-mail: fellipecoelholima@gmail.com 